\title{
Sexual Function Alteration in First Trimester of Pregnancy Among *** Women
}

Hoang Dao Nhat Linh

Quang Ngai Provincial Obstetrics, Gynecology \& Pediatric Hospital

\section{Le Sy Phuc An}

Hue University of Medicine and Pharmacy https://orcid.org/0000-0002-2951-7260

\section{Le Minh Tam}

Hue University of Medicine and Pharmacy https://orcid.org/0000-0001-6225-3108

Nguyen Vu Quoc Huy ( $\nabla$ nvqhuy@huemed-univ.edu.vn )

Hue University of Medicine and Pharmacy https://orcid.org/0000-0002-4744-7059

\section{Research Article}

Keywords: female sexual function, first trimester, pregnancy, Female Sexual Function Index

Posted Date: April 21st, 2021

DOI: https://doi.org/10.21203/rs.3.rs-436925/v2

License: (c) (i) This work is licensed under a Creative Commons Attribution 4.0 International License. Read Full License 


\section{Abstract}

Introduction: A healthy sexual life would contribute to a lasting intimate couple relationship; pregnant women were susceptible to physical, psychological and social changes leading to sexual alterations and dysfunction in pregnancy. In $* \star \star$, despite not being a novel domain, sexuality has not been extensively evaluated due to the influence of Eastern tradition, which creating promotes unsecured feelings of insecurity when talking about sex.

Aim: To investigate the female sexual function alteration during the $1^{\text {st }}$ trimester of pregnancy and some related factors among *** women.

Methods: A descriptive cross-sectional study comprising 383 women aged from 18 years old having

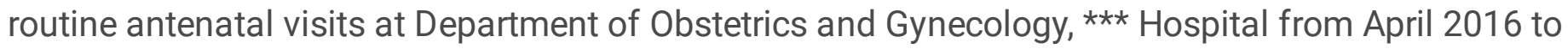
March 2017. Data were collected by interviews using is Female Sexual Function Index (FSFI) questionnaire.

Main outcome measures: Subjects' sexual function alteration, using the validated ${ }^{\star \star \star}$ version of Female Sexual Function Index.

Results: The prevalence of women with female sexual function alteration before pregnancy was $53 \%$ and in $1^{\text {st }}$ trimester was $88.8 \%$. The frequency of intercourses during $1^{\text {st }}$ trimester of pregnancy is lower than before pregnancy $(p<0.05)$. The main reasons of no sexual activity during pregnancy were fear of harming the fetus (75.1\%) and prefer not to be satisfied in the short-term rather than hurt the baby (73.5\%). Factors affected female sexual function were age, time of living-together, age of $1^{\text {st }}$ sexual intercourse, pregnancy planning, obstetrical history, sexual initiative, religion, academic level, and jobs $(p<0.05)$.

Conclusions: Sexual function alteration among first trimester pregnant women is a problem which should be considered, and medical staff should provide counseling to them to improve the quality of their sexual life and maintain normal course of pregnancy.

\section{Introduction}

Sexual activity is an important but sensitive factor in marriage. A healthy sexual life contributes to a lasting intimate relationship between partners; however, not every woman experiences a fulfilling sexual life, particularly during pregnancy. Many studies worldwide have evaluated the sexual activity of pregnant women and consistently reported a significant reduction in sexual function, especially in the third trimester. ${ }^{1-4}$ Some of this can be attributed to physical discomfort, fear of fetal adverse effects, loss of sexual desire, and dyspareunia, among other factors. ${ }^{5,6}$ Furthermore, these studies report correlations between pregnancy sexual dysfunction and maternal age, obstetrical history, gestational age, body mass index (BMI) and urinary incontinence. ${ }^{7}$ 
In $* \star *$, despite not being a novel domain, sexuality has not been extensively evaluated due to the influence of Eastern tradition, which promotes feelings of insecurity when talking about sex. Since the late 1980s, when very first studies about sexuality were published, sexual dysfunction has been under-investigated in medical science, though there have been a few studies on sexual satisfaction, which is unfortunately only one factor in sexual life..$^{8,9}$

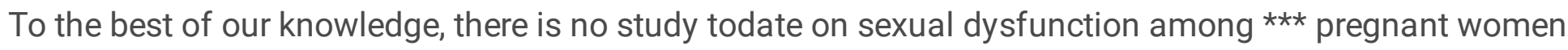
in the medical literature, either domestically or internationally. Female Sexual Function Index questionnaire has been used widely to assess its effectiveness in evaluating sexual dysfunction and its ability to distinguish between sexual dysfunction and normal function. ${ }^{10,11}$ In this study, we aim to investigate changes in sexual function during the first trimester of pregnancy using the Female Sexual Function Index, ${ }^{\star \star \star}$ translation version, and some related factors associated with these changes.

\section{Materials And Methods}

This was a descriptive cross-sectional study. Pregnant women aged at least 18 years with gestational ages from 7 - 13 weeks and 6 days who attended the Clinic of the Department of Obstetrics and Gynecology, ${ }^{\star \star \star}$ Hospital were invited to enter the study. Other inclusion criteria were women currently living with their husbands and having a stable relationship for at least 6 months. Exclusion criteria were poor obstetrical history (e.g., 3 consecutive miscarriages, history of preterm rupture of membranes), conceived via assisted reproductive technology, multiple pregnancy or disease requiring sexual abstinence during pregnancy. ${ }^{12}$

Sample size was calculated using the prevalence of sexual dysfunction among pregnant women in their first trimester of pregnancy in a study by Leite et al. ${ }^{10}$ with $p=0.466$, using the equation $n=z^{2} \cdot p(1-p) / d^{2}$, where $d=0.005$. The required sample size was 383 subjects.

Demographic data, obstetrical and sexual history of study's subjects were collected. Our study utilized the $\star * \star$ translation of Female Sexual Function Index (FSFI). ${ }^{13,14}$ The FSFI comprises a set of 19 questions that covers 6 domains of female sexual function (desire, excitement, lubrication, orgasm, satisfaction, and pain). The scores for the 4 aspects represented by questions $1,2,15$, and 16 can range from 1-5, and the scores for the remaining 2 aspects represented by questions 3-14 and 17-19 can range from 0-5. The final score is calculated by taking the sum of all elements' scores multiplied by their coefficients. The total score can vary from 2-36, where a higher score corresponds to a higher level of sexual function.

Our study was a two-phase study. The first phase was a pilot study with a sample size of 15 eligible

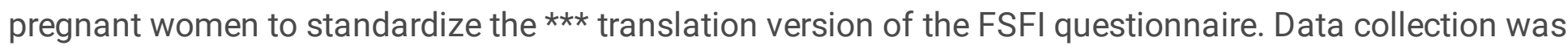
conducted in the second phase, which took place from April 2016 to February 2017. The questionnaire was completed during a personal interview at the Clinic. The pregnant women were told that their names and specific data would be confidential and that they were free to enter the study. Sexual dysfunction was defined according to Wiegel's et al. ${ }^{13}$ study, in which the cutoff of total score was 26.55 . Based on 
published work on Asian women, the cutoff points for determining disorders in each of the elements of desire, arousal, lubrication, orgasm, satisfaction, and pain are 4.28, 5.08, 5.45, 5.05, 5.04 and 5.51, respectively. ${ }^{15}$ We had 4 questions in our questionnaire to assess participants' sexual activity 4 weeks prior to pregnancy. ${ }^{16}$

Data were entered and processed using MedCalc software version 13.0.6.0. Continuous variables were presented as mean $\pm S D$, and qualitative variables were presented as frequency and percentage. Comparisons between qualitative variables were performed using the $\chi 2$ test,

whereas student's t-test was used for comparisons between continuous variables. A $p$ value $<0.05$ was considered statistically significant.

The study protocol was approved by the Ethics Committee for Biomedical Research of $\star \star \star$. All study participants provided informed consent for inclusion in the study.

\section{Results}

Among eligible 414 pregnant women who were invited to enter the study, 383 women agreed to participate in research and provided answers to the interview by medical staff. From the Table 1, the mean age of subjects was $27.44 \pm 4.5$ years, the majority (93.1\%) were 18 to 34 years old, and $6.9 \%$ $(26 / 383)$ were $\geq 35$ years old. One hundred percent of women were nonsmokers before pregnancy, $98.7 \%$ $(378 / 383)$ did not consume alcohol before pregnancy, and 1.3\% (5/383) did not drink regularly.

Table 2 shows the frequency of sexual intercourse before conception and during pregnancy, demonstrating that there was a significant reduction. A total of $64.0 \%$ of participants reported no sexual activity, in contrast to $0.0 \%$ in the preconception period. The most common reasons for not having sex were belief that sex was dangerous for the fetus, feeling tired and exhausted (30.6\%) and nausea and vomiting $(25.3 \%)$. In contrast, the main reasons for continuing sexual intercourse were to maintain the relationship (74.6\%) and to satisfy the husband's needs $(60.9 \%)$ rather than to satisfy the women's needs (34.8\%) (see Table 3).

With the cutoff of 26.55 to determine female sexual dysfunction, there was a significant increase in sexual dysfunction prevalence among first-trimester pregnant women (88.8\%) compared to nonpregnant women (53.0\%). ${ }^{13}$ We witnessed a reduction in the score for every domain of sexual function between the two points of investigation (Table 5). However, regarding the rate of dysfunction, significant differences were seen only in four out of six domains: lubrication $(p<0.005)$, orgasm $(p<0.005)$, satisfaction $(p<0.0001)$ and pain $(p<0.0001)$ (see Table $4 \& 5)$.

We evaluated some factors associated with sexual activity during pregnancy and note several findings. Female sexual dysfunction was not associated with BMI or an age gap of 2 years between partners ( $>0.05$ ). In contrast, female sexual dysfunction correlated with age group, length of the relationship, age 
of first sexual intercourse, pregnancy plan, parity, number of children, number of abortions, the initiator of sex, religion, educational attainment and female profession $(p<0.05)$.

\section{Discussion}

Sexual dysfunction is a common problem in daily life, with a prevalence of $43 \%$ according to Laumann et al., ${ }^{17}$ notably during pregnancy. Pregnancy is responsible for various physical, psychological and social changes that can affect sexual activity. ${ }^{18,19}$ Data from this study once again confirmed increasing prevalence of women with female sexual function alteration in 1 st trimester of pregnancy.

In our study, $95.8 \%$ of patients had only one sexual partner, and the mean age at first sexual intercourse was $24.04 \pm 3.25$ years, which was higher than that in the study by Haines ${ }^{20}$ and Gałązka ${ }^{4}$. This could be explained by the Eastern tradition, which discourages premarital sex and multiple partners. A total of $71.8 \%$ of our patients had never used contraception, and $14.9 \%$ reported having used condoms (see Table 1).

The incidence of sexual intercourse significantly decreased in the first trimester compared to prepregnancy, which corresponded to the findings of many other studies, such as that of Erenel et al. ${ }^{21}$ (see Table 2). A total of $64.0 \%$ reported no sexual activity during this period, which was higher than the $37.3 \%$ of subjects in the study by Haines et al. ${ }^{20}$ In this study, $75.1 \%$ of women believed that sex during pregnancy would be dangerous, a rate that was higher than that in the study by Eryılmaz et al. ${ }^{1}$ but similar to that in the study by Liu et al. ${ }^{3}$ This difference could be due to a lack of sexual information and medical consultation.

Before conception, three-quarters (77.5\%) of our patients had sex more than once a week, while the studies by Haines et al. ${ }^{20}$ (90.0\%) and Eryılmaz et al. ${ }^{1}(100 \%)$ reported a higher prevalence. ${ }^{3}$ Similarly, our study had a lower percentage of women having sex less than once a week in the first trimester than the Haines study, which could be due to differences in socioeconomic and geographic factors, although both studies took place in Asia.

In our study, women were less likely to initiate sexual intercourse (Table 1), and similar findings were reported in the study by Sacomori et al. ${ }^{22}$ The incidence of female initiators dropped heavily in the first trimester (see Table 4). In contrast, the study by Sacomori reported an increase from $5.2 \%$ to $7.2 \%{ }^{22}$ Regarding the explanation for sexual activity during pregnancy, $74.6 \%$ of women stated that they engaged in sexual activity to "satisfy the husband's need", $60.9 \%$ engaged in sexual activity because of personal desire, and $34.8 \%$ considered sex as an expression of love (see Table 4). These findings were different from the study by Moodley, in which $44 \%$ engaged in sexual activity to fulfill a personal desire, $35 \%$ to maintain the relationship, $13 \%$ to express love and $0.7 \%$ to satisfy the husband. ${ }^{23}$ Women in our study prioritized their relationships with the husband; therefore, sexual intercourse during pregnancy was mostly to satisfy the husband. Another study by Naim M comprising 150 pregnant women in Pakistan acknowledged the same situation. ${ }^{24}$ 
Table 5 shows the significant differences in sexual domains pregestational and first-trimester scores were compared $(p<0.001)$, similar to the study by Aslan et al. ${ }^{5}$ We also noted a significant decrease in the satisfaction domain during the first trimester. This finding corresponded to the studies by Oruç et al., ${ }^{25}$ comprising 158 Turkish pregnant women, DeJudicibus et al. ${ }^{26}$ and Fok et al. ${ }^{27}$ Our study reported a higher incidence of sexual dysfunction after conception, which was similar to the study by Yıldız. ${ }^{16}$ The prevalence of sexual dysfunction in each domain is shown in Table 6, where a significant difference $(p<0.05)$ is noted in all but the desire and arousal domains.

In the study by Gałazka et al., ${ }^{4}$ there was no difference in sexual dysfunction prevalence between age groups. ${ }^{20}$ However, we found some associations: prior to pregnancy, sexual dysfunction was more common in women above 30 years old. In contrast, those women experienced fewer symptoms of sexual dysfunction in the first trimester. As women grew older, they were more experienced in dealing with sexual dysfunction during pregnancy. Furthermore, according to Eryılmaz et al., ${ }^{1}$ there was a correlation between the length of the relationship and sexual dysfunction, which could be a reasonable point of view for our findings. To support this statement, we also found that sexual dysfunction occurred more frequently when the participant's relationship had lasted for more than 5 years $(p<0.005)$. The reduction in desire, intimacy and other related issues might lead to lower sexual quality.

Prior to pregnancy, the prevalence of sexual dysfunction was higher in multiparous women, which could be due to the growing pressure of and responsibility for an expanding family. ${ }^{28}$ However, in the first trimester, nulliparous women had a higher chance of sexual dysfunction in our study. Women who had previously given birth might have more experience so they could be more open to sexual intercourse during pregnancy, while nulliparous participants might feel more pressured.

Our study found that passive women whose husband was the sex initiator were more susceptible to sexual dysfunction during pregnancy. According to Sacomori et al., ${ }^{22}$ sexual arousal was correlated with the level of sexual desire; therefore, women who were the initiators would have better sexual function.

Studies by Haines, Pauls and Naldoni found no association between FSFI and educational attainment. ${ }^{11,20,29}$ In contrast, we witnessed a higher FSFI score in the advanced academic education group (college/university or above). This corresponded to the study by Güleroğlu ${ }^{28}$ showing that lower education limited the ability to self-explore and restricted accessibility to sexual health care information, leading to a lower FSFI score. In contrast, Eryılmaz et al. ${ }^{1}$ reported that women with higher education had more knowledge about the risks of having sex during pregnancy. ${ }^{1}$

Women who previously had a spontaneous abortion also feared that sexual activity would affect fetal development. In our study, the prominent reason for sexual abstinence was the belief that "sex is dangerous to the fetus", which could also be the explanation for the high prevalence of sexual dysfunction in this group of women. Although studies have demonstrated that sexual activity during 
pregnancy does not lead to adverse outcomes, such as abortion, preterm rupture of the membranes, and reproductive tract infection, this false belief remains entrenched. ${ }^{30,31}$

A higher prevalence of sexual dysfunction was also observed in the group of women who had sex prior to the age of 25 and the group of women whose couple age gap was greater than 5 years. These associations, although not prominent, might be the result of female immaturity and differences in life perspectives.

In our study, the mean preconception BMI was $19.85 \pm 2.37$, lower than that of Chang et al. ${ }^{7}$ Esposito concluded that the FSFI score was lower for obese women; however, Yaylali et al. ${ }^{32}$ reported no major association of obesity with sexual dysfunction; instead, they stated that obesity affected only a few domains of sexual function. ${ }^{32,33}$ We found no significant difference in FSFI score between the $B M 1<25$ and $B M I \geq 25$ groups $(p>0.05)$.

To the best of our knowledge, this is the first study on sexual dysfunction during the first trimester of

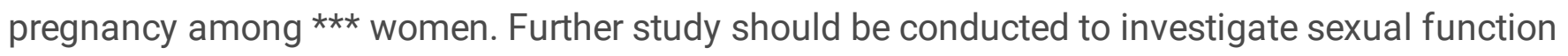
alteration throughout the pregnancy and the postpartum periods to obtain an overview of sexual dysfunction.

\section{Limitations}

Limitations of this study include its nature: this was a woman-centric study based on interviews performed by medical staff. Only if the situations of the participants' partners were taken into consideration would the study provide an objective perspective. In addition, there were socioeconomic and psychological barriers that limited the honest expression of the participants' feelings about sexual activity. Nevertheless, this study showed that sexual health care was an essential issue during pregnancy.

\section{Conclusions}

During the first trimester o pregnancy, there was a trend toward reduction in sexual activity that was due mainly to the fear of adverse fetal outcomes. Sexual dysfunction during pregnancy is a common problem that can affect women's lives. Because of the lack of reliable sources of information, women should be carefully consulted during prenatal visits regarding maintenance of their quality of sexual life.

\section{Declarations}

\section{FUNDING}

None.

\section{COMPETING INTERESTS}

The authors declare no competing interests. 


\section{References}

1. Eryilmaz G, Ege E, Zincir H. Factors affecting sexual life during pregnancy in eastern Turkey. Gynecol Obstet Invest 2004;57:103-108.

2. Hanafy S, Srour NE, Mostafa T. Female sexual dysfunction across the three pregnancy trimesters: an Egyptian study. Sex Health 2014;11:240-243.

3. Liu HL, Hsu P, Chen KH. Sexual activity during pregnancy in taiwan: a qualitative study. Sex Med 2013;1:54-61.

4. Gałązka I, Drosdzol-Cop A, Naworska B, Czajkowska M, Skrzypulec-Plinta V. Changes in the sexual function during pregnancy. J Sex Med 2015;12:445-454.

5. Aslan G, Aslan D, Kizilyar A, Ispahi C, Esen A. A prospective analysis of sexual functions during pregnancy. Int J Impot Res 2005;17:154-157.

6. Orji E, Ogunlola I, Fasubaa O. Sexuality among pregnant women in South West Nigeria. J Obstet Gynaecol 2002;22:166-168.

7. Chang SR, Chen $\mathrm{KH}$, Lin HH, Yu HJ. Comparison of overall sexual function, sexual intercourse/activity, sexual satisfaction, and sexual desire during the three trimesters of pregnancy and assessment of their determinants. J Sex Med 2011;8:2859-2867.

8. Khuat TH. Study on Sexuality in Vietnam: the known and unknown isues. Hanoi: Institute of Sociology and Population Council; 1998.

9. Linh TT. Sexual and marital satisfaction among vietnamese people. Int J Soc Sci Engl Lit 2019;3:611.

10. Leite AP, Campos AA, Dias AR, Amed AM, De Souza E, Camano L. Prevalence of sexual dysfunction during pregnancy. Rev Assoc Med Bras (1992) 2009;55:563-568.

11. Pauls RN, Occhino JA, Dryfhout VL. Effects of pregnancy on female sexual function and body image: a prospective study. J Sex Med 2008;5:1915-1922.

12. Erol B, Sanli O, Korkmaz D, Seyhan A, Akman T, Kadioglu A. A cross-sectional study of female sexual function and dysfunction during pregnancy. J Sex Med 2007;4:1381-1387.

13. Wiegel M, Meston C, Rosen R. The female sexual function index (FSFI): cross-validation and development of clinical cutoff scores. J Sex Marital Ther 2005;31:1-20.

14. Rosen R, Brown C, Heiman J, Leiblum S, Meston C, Shabsigh R, Ferguson D, D'Agostino R, Jr. The female sexual function index (FSFI): a multidimensional self-report instrument for the assessment of female sexual function. J Sex Marital Ther 2000;26:191-208.

15. Sidi H, Puteh SE, Abdullah N, Midin M. The prevalence of sexual dysfunction and potential risk factors that may impair sexual function in Malaysian women. J Sex Med 2007;4:311-321.

16. Yıldız $\mathrm{H}$. The relation between prepregnancy sexuality and sexual function during pregnancy and the postpartum period: a prospective study. J Sex Marital Ther 2015;41:49-59. 
17. Laumann EO, Paik A, Rosen RC. Sexual dysfunction in the United States: prevalence and predictors. JAMA 1999;281:537-544.

18. Anastasiadis AG, Davis AR, Ghafar MA, Burchardt M, Shabsigh R. The epidemiology and definition of female sexual disorders. World J Urol 2002;20:74-78.

19. Corbacioglu Esmer A, Akca A, Akbayir O, Goksedef BP, Bakir VL. Female sexual function and associated factors during pregnancy. J Obstet Gynaecol Res 2013;39:1165-1172.

20. Haines CJ, Shan YO, Kuen CL, Leung DH, Chung TK, Chin R. Sexual behavior in pregnancy among Hong Kong Chinese women. J Psychosom Res 1996;40:299-304.

21. Erenel AS, Eroglu K, Vural G, Dilbaz B. A pilot study: In what ways do women in Turkey experience a change in their sexuality during pregnancy? Sex Disabil 2011;29:207-216.

22. Sacomori C, Cardoso FL. Sexual initiative and intercourse behavior during pregnancy among brazilian women: a retrospective study. J Sex Marital Ther 2010;36:124-136.

23. Moodley J, Khedun SM. Sexual activity during pregnancy: a questionnaire-based study. South Afr J Epidemiol Infect 2011;26:33-35.

24. Naim M, Bhutto E. Sexuality during pregnancy in Pakistani women. J Pak Med Assoc 2000;50:38-44.

25. Oruç $S$, Esen A, Laçin S, Adigüzel H, Uyar Y, Koyuncu F. Sexual behaviour during pregnancy. Aust N Z J Obstet Gynaecol 1999;39:48-50.

26. DeJudicibus MA, McCabe MP. Psychological factors and the sexuality of pregnant and postpartum women. J Sex Res 2002;39:94-103.

27. Fok WY, Chan LY, Yuen PM. Sexual behavior and activity in Chinese pregnant women. Acta Obstet Gynecol Scand 2005;84:934-938.

28. Güleroğlu FT, Gördeles Beşer N. Evaluation of sexual functions of the pregnant women. J Sex Med 2014;11:146-153.

29. Naldoni LM, Pazmiño MA, Pezzan PA, Pereira SB, Duarte G, Ferreira CH. Evaluation of sexual function in Brazilian pregnant women. J Sex Marital Ther 2011;37:116-129.

30. Kontoyannis M, Katsetos C, Panagopoulos P. Sexual intercourse during pregnancy. Heal Sci J 2012;6:82-87.

31. Mai C. The changes of sexuality in thai women during pregnancy. J Med Assoc Thai 2006;89 Suppl 4:S124-S129.

32. Yaylali GF, Tekekoglu S, Akin F. Sexual dysfunction in obese and overweight women. Int J Impot Res 2010;22:220-226.

33. Esposito K, Ciotola M, Giugliano F, Bisogni C, Schisano B, Autorino R, Cobellis L, De Sio M, Colacurci $\mathrm{N}$, Giugliano D. Association of body weight with sexual function in women. Int J Impot Res 2007;19:353-357.

\section{Tables}


Table 1. Characteristics of study subjects.

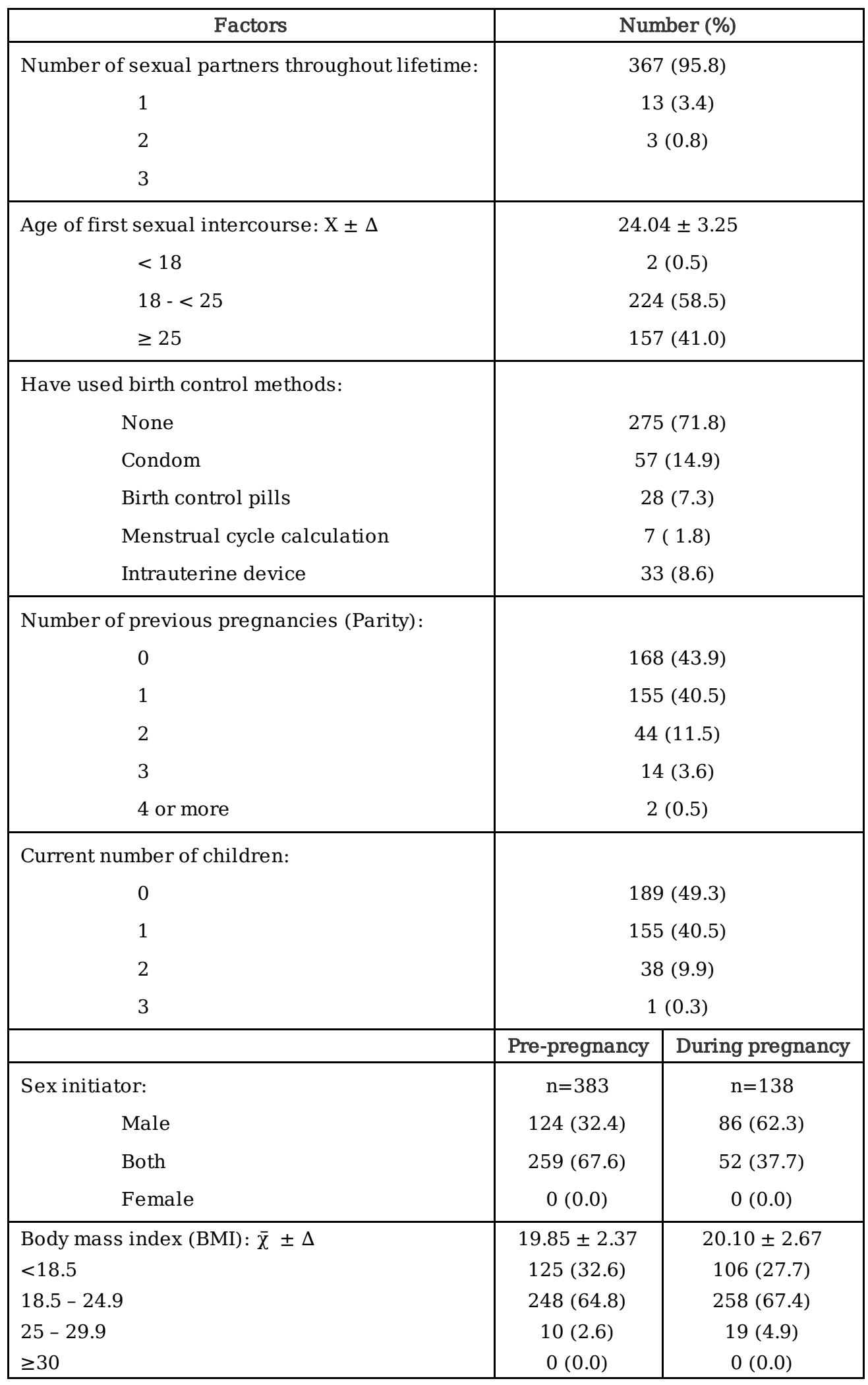

Table 2. Rate of sexual activity during the first trimester of pregnancy. 


\begin{tabular}{|c|c|c|c|}
\hline Rate & Pre-pregnancy (n=383) & During pregnancy $(\mathrm{n}=383)$ & $\mathrm{p}$ \\
\hline None & $0(0.0)$ & $245(64.0)$ & $\mathrm{p}<0.0001$ \\
Once per month & $37(9.7)$ & $50(13.1)$ & $40(10.4)$ \\
Twice per month & $49(12.8)$ & $22(5.7)$ & $23(6.0)$ \\
Once per week & $86(22.5)$ & $3(0.8)$ & \\
Twice per week & $98(25.5)$ & $13(29.5)$ & \\
\hline
\end{tabular}

Table 3. Reasons for not having / having sexual activity during the first trimester of pregnancy.

\begin{tabular}{|c|c|}
\hline Reasons for not having sexual activity during pregnancy & $\mathrm{n}=245$ \\
\hline Tired, exhausted & $75(30.6)$ \\
\hline Not being physically comfortable & $11(4.5)$ \\
\hline Nausea, vomiting & $62(25.3)$ \\
\hline Would rather abstain for sometimes than risk hurting fetus & $180(73.5)$ \\
\hline Decline in sex drive & $18(7.3)$ \\
\hline No longer feel oneself attractive & $2(0.8)$ \\
\hline Believe having intercourse during pregnancy is dangerous & $184(75.1)$ \\
\hline Worried wrong intercourse positions can affect fetus & $8(3.3)$ \\
\hline Fear of miscarriage & $61(24.9)$ \\
\hline Fear of stillbirth & $1(0.4)$ \\
\hline Husband declines intercourse & $9(3.7)$ \\
\hline Fear having intercourse is painful & $2(0.8)$ \\
\hline Reasons for having sexual activity during pregnancy & $\mathrm{n}=138$ \\
\hline To satisfy one's personal needs & $48(34.8)$ \\
\hline To satisfy husband's needs & $84(60.9)$ \\
\hline Maintain relationship & $103(74.6)$ \\
\hline Reduce stress & $8(5.8)$ \\
\hline Relax & $4(2.9)$ \\
\hline A must in marriage & $1(0.7)$ \\
\hline Express one's love & $24(17.4)$ \\
\hline
\end{tabular}

Table 4. FSFI score range. 


\begin{tabular}{|c|c|c|c|}
\hline Domain & Prepregnancy $(\mathrm{n}=383)$ & During pregnacy $(\mathrm{n}=383)$ & $\mathrm{S} 1$ to $\mathrm{S} 0$ \\
\hline Desire & $3.45 \pm 0.91$ & $2.46 \pm 0.98$ & $\mathrm{p}<0.0001$ \\
Arousal & $3.83 \pm 0.97$ & $1.16 \pm 1.69$ & $\mathrm{p}<0.0001$ \\
Lubrication & $4.77 \pm 0.96$ & $1.49 \pm 2.15$ & $\mathrm{p}<0.0001$ \\
Orgasm & $4.16 \pm 1.26$ & $1.34 \pm 1.98$ & $\mathrm{p}<0.0001$ \\
Satisfaction & $5.14 \pm 0.88$ & $3.52 \pm 1.29$ & $\mathrm{p}<0.0001$ \\
Pain & $4.67 \pm 1.04$ & $1.50 \pm 2.16$ & $\mathrm{p}<0.0001$ \\
\hline Total score & $26.02 \pm 4.29$ & $11.47 \pm 9.36$ & $\mathrm{p}<0.0001$ \\
\hline
\end{tabular}

Table 5. Sexual dysfunction prevalence in individual domain.

\begin{tabular}{|c|c|c|c|}
\hline Sexual dysfunction domains & $\begin{array}{c}\text { Prepregnancy } \\
(\mathrm{n}=203)\end{array}$ & During pregnancy (n=340) & S1 to S0 \\
\hline Desire & $196(96.6)$ & $334(98.2)$ & $\mathrm{p}>0.05$ \\
\hline Arousal & $203(100.0)$ & $340(100.0)$ & - \\
\hline Lubrication & $185(91.1)$ & $335(98.5)$ & $\mathrm{p}<0.05$ \\
\hline Orgasm & $198(97.5)$ & $340(100.0)$ & $\mathrm{p}<0.05$ \\
\hline Satisfaction & $136(67.0)$ & $319(93.8)$ & $\mathrm{p}<0.0001$ \\
\hline Pain & $181(89.2)$ & $333(97.9)$ & $\mathrm{p}<0.0001$ \\
\hline
\end{tabular}

